\title{
Identification of homogeneous areas from urban-environmental vulnerabilities: La Plata, Buenos Aires, Argentina
}

\author{
J. Esparza, G. Viegas \& I. Martini \\ Research and Policy Institute of the Built Environment, La Plata Faculty \\ of Architecture, La Plata National University, Argentina
}

\begin{abstract}
The urban growth of recent decades has created a significant imbalance between the environment, the territory and its inhabitants. This process therefore results in environmental issues such as pollution, overcrowding, excessive accumulation of debris and flooding of urbanized areas, among others. In this paper, the environment and the perception of the people (through surveys), are unmeasured and located in the territory, in order to recognize common ground between the three and to identify areas of urban-environmental vulnerability (AU-AV).

It explains a technical-instrumental system, developed from a relational methodology of information, forming a body of data with which to identify the issues raised. In this case, the analysis information, allowed discrimination: (i) the geographical location of the perception of the people; (ii) the degree of influence of territorial and environmental variables; (iii) identification of areas which are affected by this influence. Recalling that, given the complexity of collision, we must work from methodological triangulation, where information must respond to quantitative and qualitative methods whose implementation can be independent or combined.

The Inverse Distance Weight (IDW) interpolation method was used, pertaining to the program Arc Gis 9.3. This method incorporates the information of each survey territorialized (as information points) and calculates the value of its attribute depending on the information of the surrounding points, which allow for obtaining graphical results (maps). The maps have been a key figure input to identifying these areas. Variables submitted for appraisal of the perception of people, allowed us to obtain and identify certain detailed issues as intrinsic
\end{abstract}


directionality between the response and the observed and causal territorialization of them.

Keywords: urban/environmental vulnerability, technical/instrumental system, graphical results.

\section{Introduction}

Urban characteristics in recent times have been linked closely, through their study and intervention, with the environmental aspects. The dynamics of urban and population growth have generated considerable imbalances with respect to the surrounding medium. Consequently, supply systems and services (from the energy aspect to waste generation) have collapsed as a result of contemporary urban life. The resulting environmental damage or costs threaten future productivity, health and quality of life of its inhabitants [1]. Goytre explains: "On the basis of this situation (...), it is highlighted that (...) citizens have lost control of the ability of over many activities that occur in their urban environment. With the development of the modern state, and in an accelerated way in the second half of the twentieth century, decisions on urban activities(production, exchange and consumption), have been emancipated from the places where they occur, regardless of the needs both local natural capital as the human development of its inhabitants” [1].

This generalized urban-environmental crisis, suggests that the formulation of methodologies reliable and capable of understanding the urban system from its complexity, would minimize the different vulnerability levels. In the city, the territorial vulnerability arises from factors such as excessive population growth, modes of land use, exploitation of resources, but also by the functional, institutional and political lack and default. In relation to what is exposed above, it should add as synthesis, that the environmental issues have become the focus of the question and discussion of contemporary urban.

\section{Methodology}

The study of vulnerability can be invoked from different scales and interdisciplinary approach. In this case, the study of the territory can recognize, among other things, urban dynamics [3], mode and type of settlements, the behavior of networks and building infrastructure and communication modes.

Thus, it appeals to a relational system [2] based on the juxtaposition and overlap of variables from different systems and scales. This scheme, which appeals to the bidirectional processes, requires a comprehensive study based on the multiplicity of results. It can be said that if it count with a methodology and tools that enable the collection of systematic information, it will allow for recognizing on one hand, the contributions that are manifested in the observed reality and on the other an accurate diagnosis of the urban situation.

To this purpose it is necessary to develop a mechanism in order to obtain Homogeneous Areas of Urban-Environmental Vulnerability (HAU-EV) on which to act from a policy of comprehensive planning and management. 
Therefore it is necessary to define and quantify the participation of each of the variables involved, from: (i) the conception of the variables as "layers", as perceived by each person; (ii) the conception of them as a data set to obtain measurable results in environmental urban order.

Variables such as "relatable" layers intersect generating different possible results. From the variables approach and main objective, it is proposed to obtain and identify HAU-EV from the superposition and juxtaposition of the different variables involved. They are presented in Table 1.

Table 1: Outline of the object of study and the methodological and operational conceptualization.

\begin{tabular}{|c|c|c|c|c|}
\hline $\begin{array}{c}\text { Macro } \\
\text { Variable }\end{array}$ & Variable & Relation value & $\begin{array}{c}\text { Superposition } \\
\text { method }\end{array}$ & Representation \\
\hline \multirow{6}{*}{$\begin{array}{c}\text { V1. } \\
\text { Territorial } \\
\text { Variable }\end{array}$} & \multirow{2}{*}{$\begin{array}{l}\text { V1a. Urban } \\
\text { Consolidation }\end{array}$} & Building Density & \multirow{7}{*}{$\begin{array}{c}\text { Mapping and } \\
\text { geospatial analysis. }\end{array}$} & \multirow{14}{*}{$\begin{array}{c}\text { Graphic- } \\
\text { numerical } \\
\text { outputs (maps) }\end{array}$} \\
\hline & & Coverage of basic inf services & & \\
\hline & \multirow[t]{2}{*}{$\begin{array}{l}\text { V1b. Road } \\
\text { infrastructure }\end{array}$} & $\begin{array}{l}\text { Primary and secondary } \\
\text { corridors }\end{array}$ & & \\
\hline & & Connectivity between areas & & \\
\hline & \multirow{2}{*}{$\begin{array}{l}\text { V1c. Socio- } \\
\text { economic Level }\end{array}$} & Income of the population & & \\
\hline & & Unsatisfied Basic Needs & & \\
\hline \multirow{6}{*}{$\begin{array}{l}\text { V2. } \\
\text { Environ- } \\
\text { mental } \\
\text { Variable }\end{array}$} & \multirow{4}{*}{$\begin{array}{l}\text { V2a.Pollution and } \\
\text { environmental } \\
\text { degradation }\end{array}$} & Flood areas & & \\
\hline & & Dumps areas & \multirow[t]{5}{*}{ First integration results } & \\
\hline & & Noise Pollution & & \\
\hline & & Air Pollution & & \\
\hline & \multirow[t]{2}{*}{ V2b. Green Spaces } & Squares and boulevards & & \\
\hline & & Urban and Regional Parks & & \\
\hline \multirow{2}{*}{$\begin{array}{c}\text { V3. } \\
\text { Subjective } \\
\text { Variable }\end{array}$} & \multirow[t]{2}{*}{ V3a. Subjectivity } & Surveys & \multirow{2}{*}{$\begin{array}{l}\text { Mapping and Spatial } \\
\text { Analysis }\end{array}$} & \\
\hline & & Newspaper clippings & & \\
\hline
\end{tabular}

\subsection{Study and processing of variables}

When working with information from different media, it is necessary to incorporate a methodology called "methodological triangulation", from which the problem can be approached from qualitative and quantitative methods simultaneously. In this case, the implementation can be independent or combined, since each of the methods has advantages and disadvantages regarding the collection of information [3]. Consequently, the proposed variables are oriented to investigate territorial, environmental and perceptive aspects in the urban context, in this case La Plata City. The following systematization variables tools are used:

\subsubsection{Geographic Information System (GIS)}

The specialization of the variables proposed is via a numerical database, from a Geographic Information System (GIS), as an ArcView type, which allows viewing and obtaining results from a geographical-territorial context. Using this methodology instrumentation allows conforming different results maps, which enables viewing homogeneous areas characterized from each aspect and variable analyzed.

From the use of this tool, different maps were built that correspond to different "layers" containing information on the variables analyzed. As stated 
before, depending on the degree of information to be analyzed or crosslink, the layers allow obtaining graphical information. If for example, territorial and environmental aspects are superposed, such as urban consolidation and green spaces, it can begin to recognize through georeferenced results (GIS), the relationship between the built and natural environment.

This crossing will only recognize certain holistic data. In order to become part of a recognizable everyday reality, these data should be weighted or recognized by people. Here, it is reported the formation of the city of La Plata and its location with respect to the Autonomous City of Buenos Aires (Province of Buenos Aires) (see Figures 1-3).

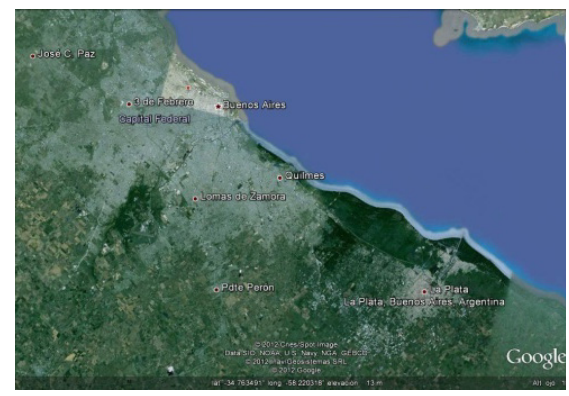

Figure 1: La Plata City and Autonomous City of Buenos Aires.

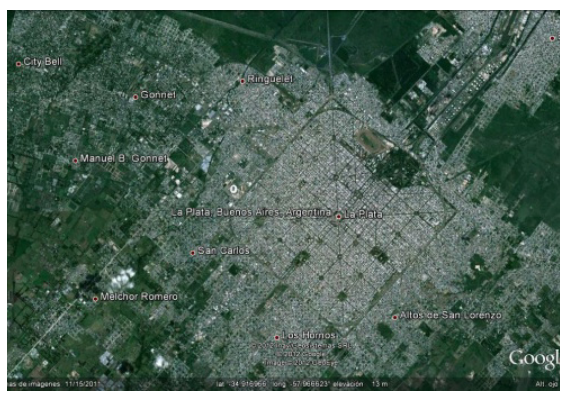

Figure 2: $\quad$ La Plata City.

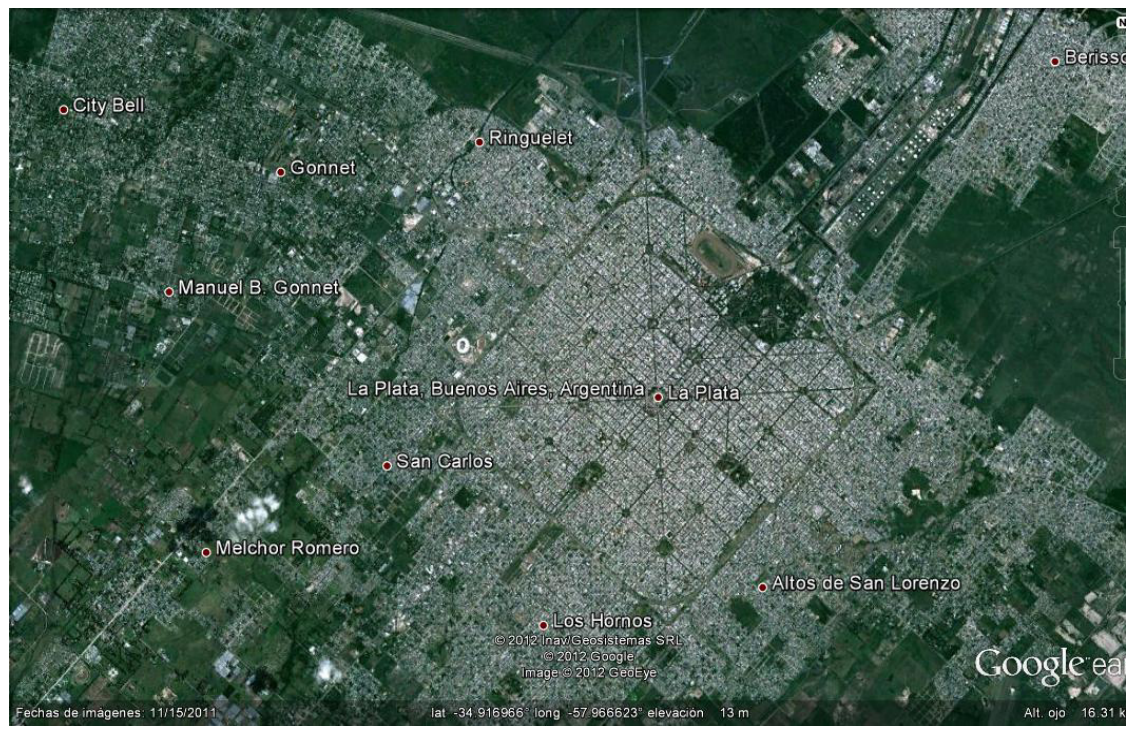

Figure 3: $\quad$ La Plata City and surrounding area. Source: Google Earth. 


\subsection{Variables overlapping}

To identify HAU-EV, certain patterns of “clustering” and juxtaposition of these variables should be known, and as noted above, from different approaches. Figure 4 shows the three territorial variables under study, their overlap and the defined areas in a first approximation level.

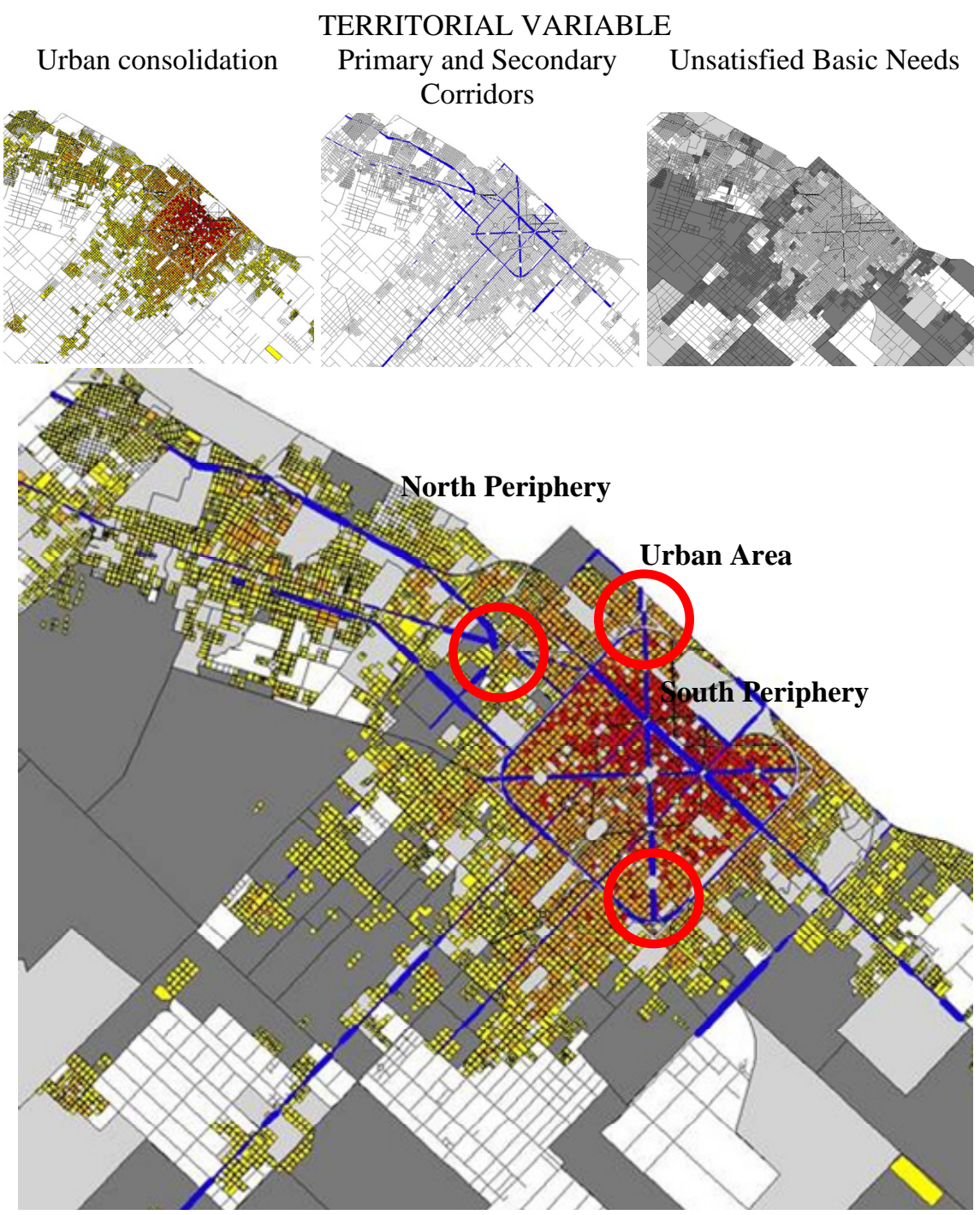

Figure 4: $\quad$ Map of the juxtaposition of the environmental variables. 
Analyzing the resulting map we can conclude that: (1) in the Central area, the three maximum values of the variables analyzed are shown: the high occupancy (urban consolidation), extremely busy main roads and those homes without UBN. In the same way, we can distinguish three areas: a central one, other in the far North, and the other in the extreme Southwest, where the mixture of situations begins to appear; (2) in the Northern suburbs (to Buenos Aires) an intermediate situation exists. Here, the consolidation is medium-low, but with the existence of busy roads, such as the "General Belgrano Road" and "Centennial Road" and a high percentage of homes without UBN; (3) in the South periphery (towards Villa Elvira), consolidation is mostly low, where the only way of concurrency is the 7th Avenue. In this case, there are a high percentage of households with UBN. Moreover, the issue related to the territorial transformations processes of recent times coexist, which the expansive phenomenon had occurred towards the Federal Capital. In this sense, if you look at the map of UBN, a vast difference between the two peripheries can be recognized.

The following step is to unfold the study of the environmental variables. It is important to remember that both the study of the environmental and territorial variables, the inhabitants' perceptions should be incorporated as the main point for the recognition of the observed reality (see Figure 5).

Analyzing the resulting map it can be concluded that: (1) there are two critical or vulnerable areas, mainly by the presence and convergence of two or more of these variables. In the center area, pathologies related to air pollution (produced by public transport, mostly) and sound pollution converge, by the existence of commercial and administrative area in that sector. Furthermore, the failure and lack of drainage system complicates the water running in rainy days. The system has been collapsed in the last years by the increasing pressure on the land cost; (2) in the area of the Northern suburbs (Gonnet, see Figure 3) pathologies such as floods, dump areas and sound pollution converge. The detailed study of the environmental aspects [4] has allowed us to highlight the reality state that exists between the objective data that we developed previously, and those related to the subjective one, where the opinion and/or perception of inhabitants allows verifying such situation (morning Journal "El Dia”, 2009); (3) in the area of the Southern suburbs (Los Hornos, see Figure 3), pathologies such as dump areas and flooded areas converge. This is particularly due to poor waste collection system, since in the area occurs only three (3) times a week, not daily as in the Central area.

\section{Homogeneous areas of urban environmental vulnerability analyzed from perception}

The opinion (of subjective character) can become objective and measurable when it relates to certain parameters pertaining to the territorial and environmental variables. The subjective data collection tools are as follows: 


\subsection{Surveys}

The survey was structured from what Corraliza [5] called "affective dimensions of the environment". It allows recognizing the degree of appreciation of respondents from "adjective pairs" qualifying the observed environment. In this research, these adjectives have been re-structured in terms of a better understanding for the respondents as a first test approach, many of the words used by Corraliza at work, were not included respondents from the local environment: (1) Pleasing Factor: "pleasant/unpleasant”, “attractive/repulsive”, "cozy/inhospitable”; (2) Activation Factor: "quiet/busy”, "village/desert”, "lively /discouraged”, "silent/restless"; (3) Impact Factor: "significant/ insignificant”, “colorful/indifferent”, "flashy/discreet”, "singular/regular”; (4) Control Factor: “comfortable/disturbing”, "safe/unsafe”, “care/careless”, "light/dark”.

To overlay information from different media (objective and subjective) is to use a rating system which has allowed the survey structure from the factors and variables mentioned and depending on the possible answers, where the ranges vary 0.1 to 1.0 [6]. For example, if the respondent believes that the environment is "Very pleasant" 0.1 as ceiling serious scale, "Pleasant", 0.3, "Little pleasant" 0.5 and "Unpleasant", would be 1.0 .

\subsection{Newspaper clippings}

The press screening can be used as analysis method to evaluate the opinion of people. In this sense, it was proposed as an alternative methodology, the daily monitoring of the region, "The Day" to know what the readers assessments regarding these variables. In this evaluation system, the perceptions of local residents were assigned a value (and qualification) to each of the issues, which determine the level of satisfaction of the inhabitants. For the case of territorial variables, the assigned scale has values of 10 to 1 , with 10 being the maximum ceiling of that scale (Good) 5.0 (Regular), 1.0 (Bad) and 0.0 (without data). In the case of environmental variables, the scale includes values from 0.1 to 1.0 determines the level of satisfaction of the inhabitants, the floor being 0.1 scale (very noticeable), 0.3 (Notorious), 0.5 (inconspicuous) and 1.0 (not perceive).

For this research, the degree of perception can be appreciated of the inhabitants of two of the variables coincident with those referred to in Table 1: air and sound pollution. It should be noted that as part of the implementation methodology, not only the opinions and/or perceptions by neighbors were required, but also the location and territorial reference point (Neighborhood and/or address of the respondent). Below are a series of maps that represent the perceptions of people in the city of La Plata in different parts of it (see Figure 6).

\section{Results}

As has been said, the opinion of people can be considered from two instruments: surveys and newspaper clippings. Accordingly, the opinions (subjective 


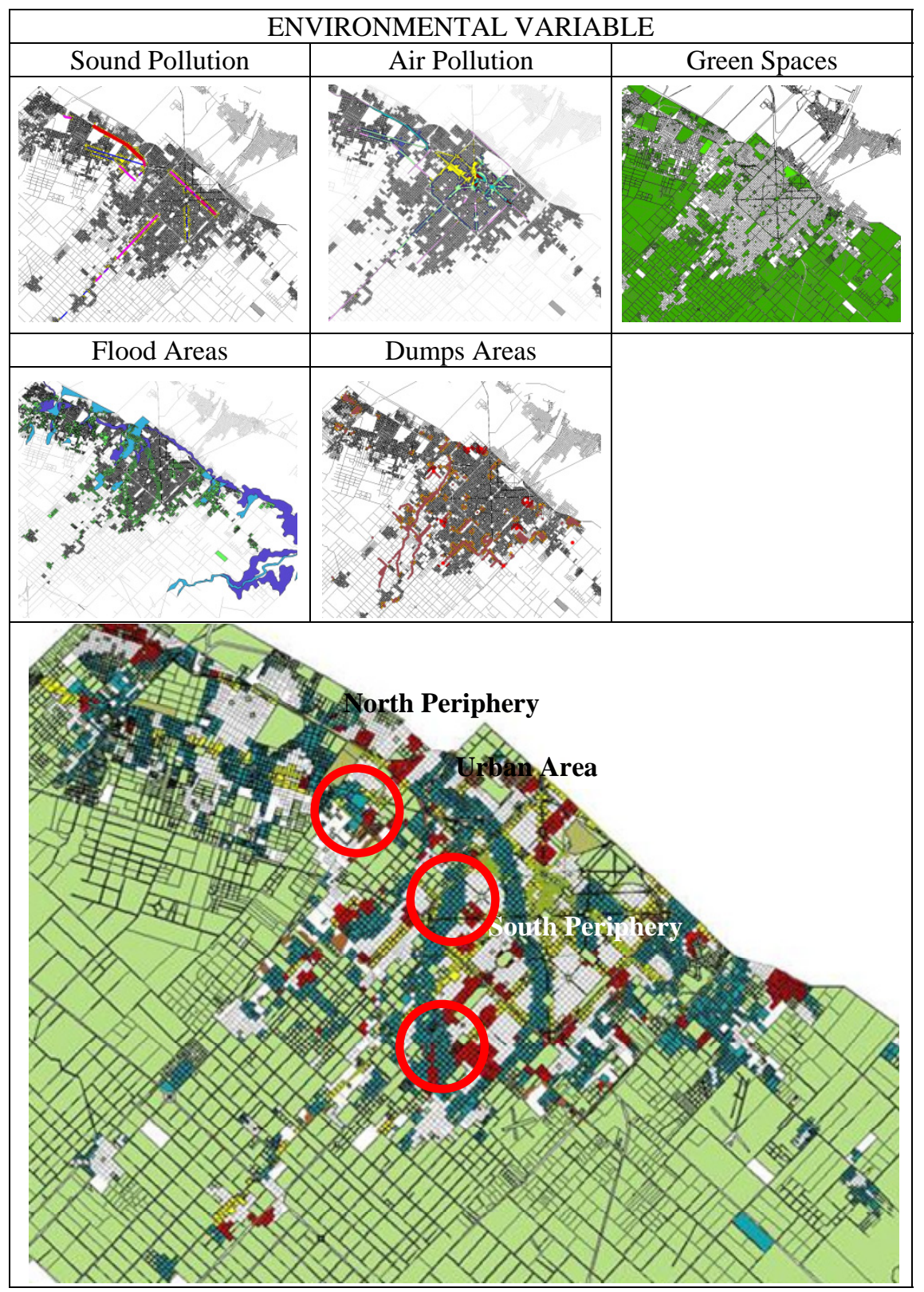

Figure 5: $\quad$ Map of the juxtaposition of the environmental variables. 


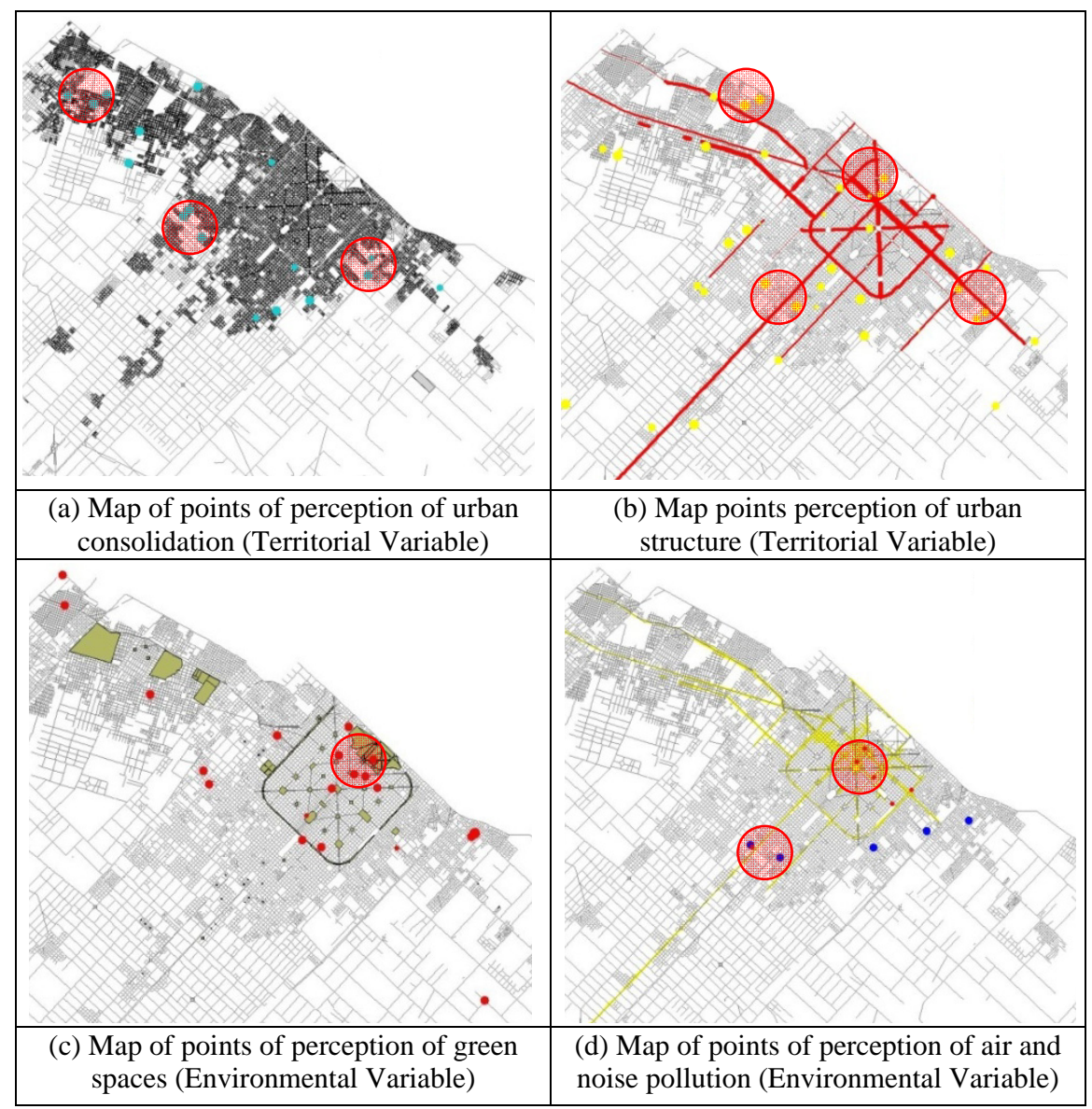

Figure 6: $\quad$ Maps of points of perception of (a) urban consolidation, (b) urban structure, (c) green spaces and (d) air and noise pollution.

character), were systematized in a data matrix, from which results are integrated with those "objectives" and standardized from attributes.

It was used the IDW interpolation method (gravitational or inverse distance), belonging to the extensions included in the Arc GIS 9.3. This method incorporates the information of each territorialized points (in this case, surveys) and calculates the value of its attribute depending on the information of the surrounding points.

In this sense the determination of the point to interpolate the greater the closer you are to another point in the same informative feature [7]. So, each of the subjective variables were "interpolate" through this system, obtaining areas of influence of the different responses obtained. 


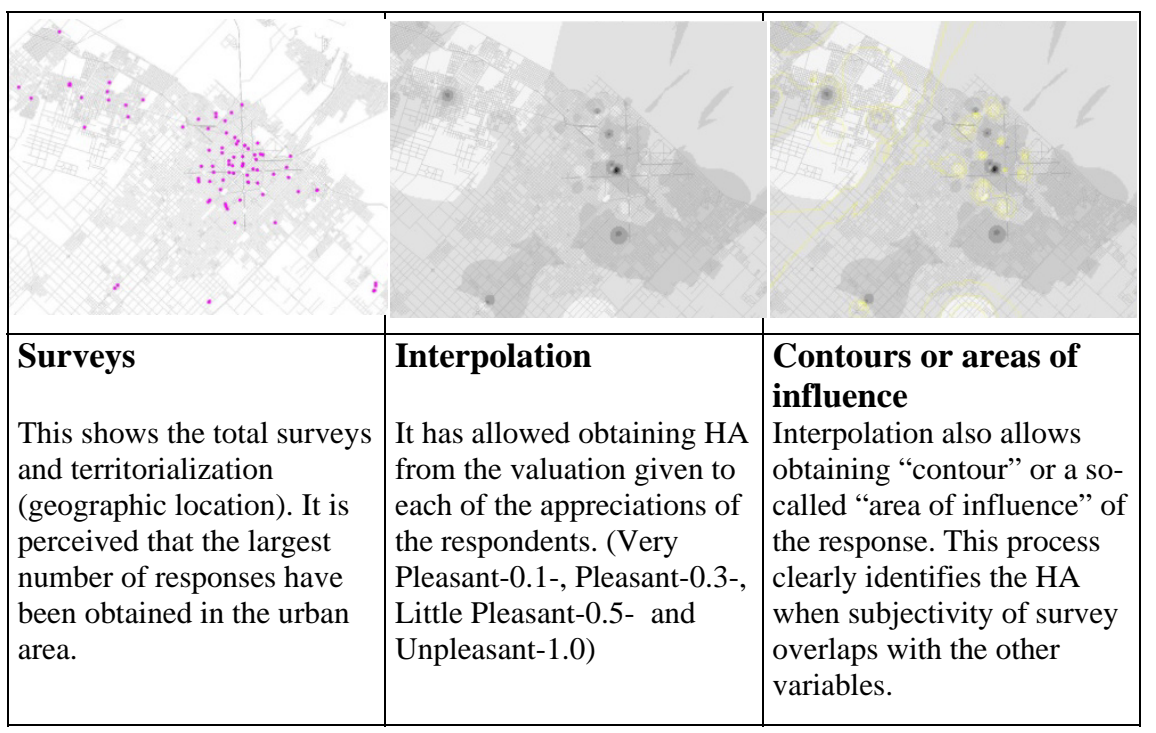

Figure 7: Location of respondents (surveys), the interpolation and identification of affected areas.

Only as a methodology, is developed "Activation Factor", which gathers the responses of the variables quiet, village, lively and silent. They made it possible to know whether or not respondents perceive the movements and dynamics of the city themselves, that is, those activities that at certain times, days or moments attract or disperse the population. This may depend on factors such as proximity to places and/or cultural events, commercial and administrative sectors or major public spaces (such as parks or walks).

The "Activation Factor" in its four variables was crisscrossed with urban consolidation and garbage dumps, allowing obtaining and identifying homogeneous areas in relation to the number of people affected by them. In this respects recognized the compatibility between responses and objective reality, where those unsatisfactory characters are located in areas where there are low consolidation or dumps. It is worth mentioning that these variables are particularly useful to identify which areas would be vulnerable, from which, acting from a management policy and integrated planning. Then village variable develops exemplary of the proposed methodology (see Figure 8).

In the graphical results was observed that most of the responses have been "village". In this case, they are located in areas of high and medium consolidation, both the central and the periphery areas (toward Villa Elisa). In Figure 9, the interpolations can be seen.

The answers "very village" is mostly, and consequently, in the greater consolidation area in the center of central area. Those who responded "little village”, are located mostly in the northern periphery, and those who responded "desert", are located in the southern suburbs, where there is a low area of the city consolidation. 


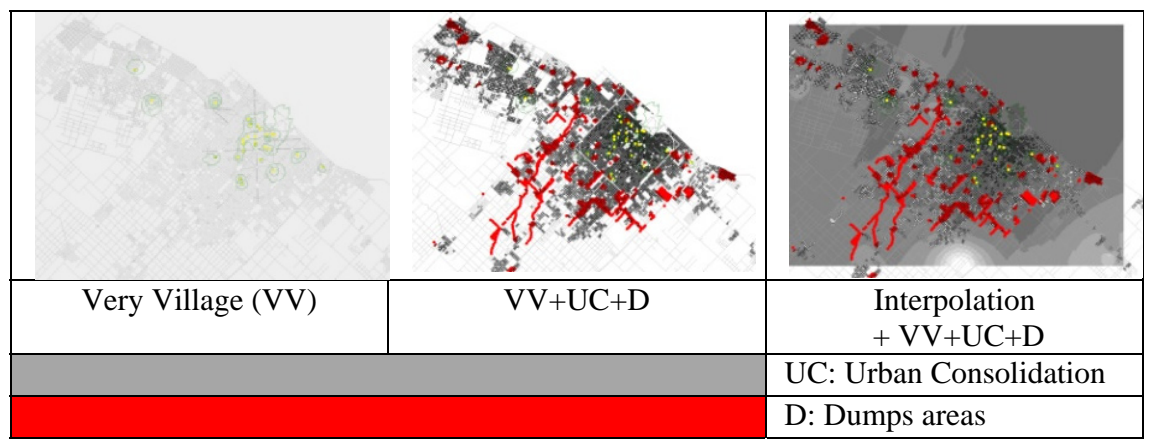

Figure 8: $\quad$ Activation Factor - village variable.

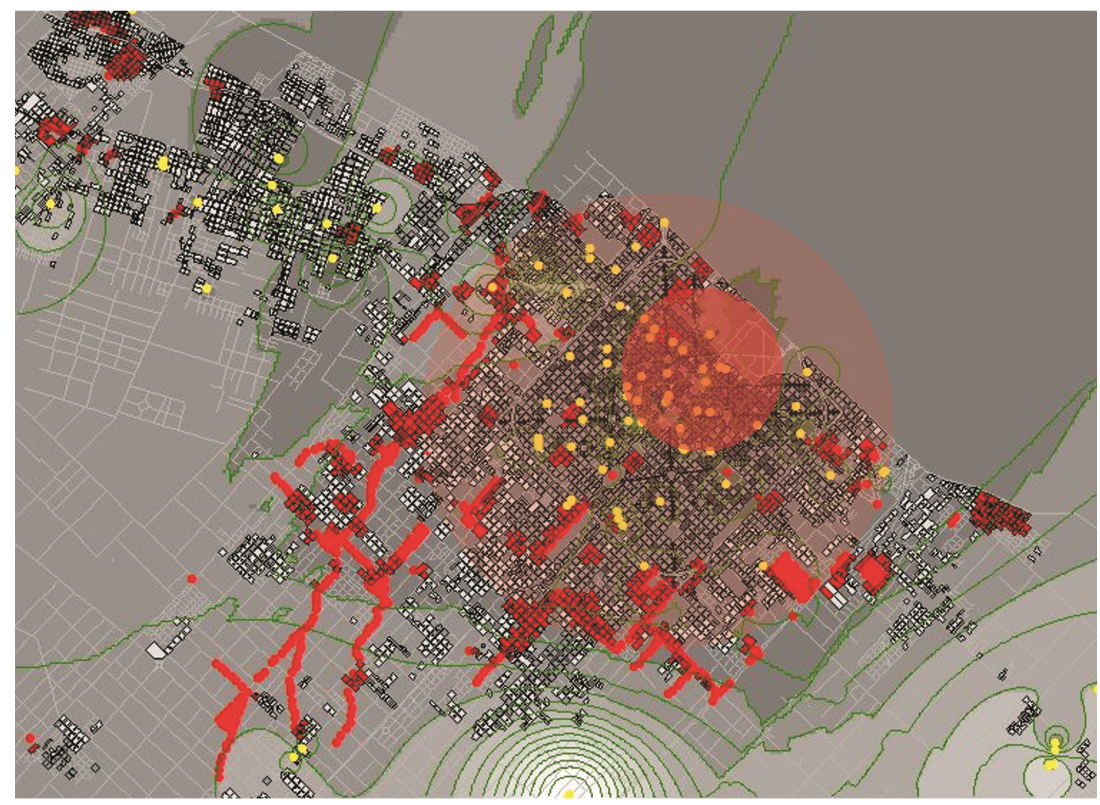

Figure 9: Homogeneous areas of vulnerability from the village variable.

From these observations, two issues can be defined: first, the direct relationship between observed reality and the objective of territorial variable and, second, the relationship between the degree of consolidation and dumps areas. For example, in areas of high consolidation, garbage collection is performed daily while in certain sectors of the periphery only performed three times a week. 


\section{Conclusions}

Both the territory and the environment and even perceptions of the inhabitants, as the weighting factor of the observed, have been unmeasured and located in the territory, in order to identify points of encounter between the three, and thus, to identify homogeneous areas.

In the synthesis of the variable map village, have identified two (2) homogeneous areas, which particularly are overlapped. One of them is the one that gathers responses located on the high and medium areas of consolidation, where converge the largest number of "village" and the second, over the area where the answers converge "very village" in the Central area.

In this regard, and as a general conclusion, in the studied region have been identified three (3) areas defined not only by the number of respondents, but the disparity in their answers. The first area, which encompasses the area consequently most people, is the center area where nucleate generally satisfactory responses, regulated by the improved situation of the objective variables. The second area is that in the northern periphery (Tolosa, Gonnet, City and Villa Elisa Bell (see Figure 3)). It is known that the growth and transformation of the territory has been given in an important pattern of land occupation, to this area. The third area, located in the southern periphery (toward Villa Elvira (see Figure 3)) gathers unsatisfactory issues, where factors such as lack of security, are highlighted.

The answer would be to generate comprehensive proposals from the various administrative and governmental estates, from decentralizations of cultural and social, as well as from those activities functional and livelihood of the entire studied territory. It is understood that each of these proposals requires some accompaniment of the inhabitants from their civic duty.

\section{References}

[1] Goytre, Félix Arias. (2001) Problemática Urbana Actual. Instituto Juan de Herrera. Madrid. España. ISSN: 1578-097x.

[2] Codd, E.F. (1970). Un modelo relacional de datos para grandes bancos de datos compartidos. IBM Research Laboratory, San Jose, California.

[3] Esparza, J.; Dicroce, L.; Martini, I.; Rosenfeld, E.; Discoli, C.; Ramirez Casa, J. (2008). Análisis metodológico de las herramientas de evaluación de la opinión/percepción en el marco de un Modelo de Calidad de Vida Urbana. Revista Avances en Energías Renovables y Medio Ambiente. Vol. 12, ISSN 0329-5184.

[4] Esparza, J.; Martini I.; Discoli, C. (2011). Metodología para el análisis detallado de los aspectos urbano-ambientales en la escala puntual de la ciudad. Revista Avances en Energías Renovables y Medio Ambiente. Vol. 15, ISSN 0329-5184.

[5] Corraliza Rodríguez, José Antonio. (2003). Emoción y ambiente. Psicología ambiental, Juan Ignacio Aragonés. Editorial Pirámide, Madrid. 
[6] Rosenfeld, E. (2005). Modelo de Calidad de Vida Urbana. Determinación de índices y espacialización de áreas homogéneas. Revista avances en energías Renovables y medio ambiente. ISSN 0329-5184. Vol. 6. Tomo 1. pp. 01.4148. INENCO - UNSa, Salta.

[7] Dicroce, L.; Discoli, C.; Martini, I.; Esparza, J.; San Juan, G.; Rosenfeld, E. Aplicación de un Modelo de Calidad de Vida Urbana (MCVU) con datos oficiales extraídos del censo nacional. (2009). Revista Avances en Energías Renovables y Medio Ambiente. Vol. 13, ISSN 0329-5184.

[8] Domingo Gómez Orea (1999). Evaluación del Impacto Ambiental. Un instrumento preventivo para la gestión ambiental. Ediciones Mundi-Prensa, Editorial Agrícola Española. 